Revista

A Cor

das Letras

\title{
Haicai: Sequência Didática na perspectiva do Letramento Literário
}

\author{
Haicai: Didactic Sequence in the perspective of Literary Literacy
}

\author{
Walméria Oliveira Dantas \\ Universidade Estadual de Feira de Santana \\ Feira de Santana, Bahia, Brasil \\ Alana de Oliveira Freitas El Fahl \\ Universidade Estadual de Feira de Santana \\ Feira de Santana, Bahia, Brasil
}

\begin{abstract}
Resumo: Este artigo traz um recorte da dissertação de mestrado Flash poético: uma experiência de leitura e produção de haicais e fotografias na perspectiva do letramento literário. Trata-se de uma pesquisa de base qualitativa com foco na pesquisa-ação, que apresenta uma proposta de intervenção baseada na metodologia de sequência didática aplicada à leitura e a escrita de haicais, inspirados em fotografias autorais. O objetivo é contribuir para o aumento dos níveis de letramento literário de uma turma de alunos do sétimo ano do ensino fundamental. A pesquisa foi realizada no Colégio Estadual José Ferreira Pinto, na cidade de Feira de Santana/BA. Neste recorte, apresentamos a Sequência Didática e parte do material didático utilizado durante a intervenção. Os resultados obtidos durante o estudo evidenciaram a importância da utilização de materiais didáticos que dialoguem com a realidade e as experiências de vida dos alunos, possibilitando a aprendizagem na perspectiva do Letramento Literário.
\end{abstract}

Palavras-chave: Letramento literário. Haicai. Sequência Didática.

\begin{abstract}
This article brings a cut of the master's thesis Poetic Flash: an experience of reading and producing haiku and photographs from the perspective of literary literacy, it is a qualitative research focused on action research, which presents a proposal of intervention based on the methodology of didactic sequence applied to the reading and the writing of haiku, inspired by photographic authors. With the objective of contributing to the increase of the levels of literary literacy of a group of students of the seventh year of elementary school. The research was carried out at the José Ferreira Pinto State College, in the city of Feira de Santana / BA. In this section we present the Didactic Sequence and part of the didactic material used during the intervention. The results obtained during the study evidenced the importance of the use of didactic materials that dialogue with the reality and life experiences of the students, enabling them to learn from the perspective of Literary Literacy
\end{abstract}

Keywords: Literary literacy. Haicai. Following teaching

\section{INTRODUÇÃO}

Neste artigo, dentre os pressupostos teóricos e metodológicos que fundamentam a pesquisa, destacamos considerações baseadas em Soares (2001), Cosson (2014) e Paulino (2010) sobre Letramento e Letramento Literário. Não poderíamos deixar de abordar o

* Mestre Letras (ProfLetras/UEFS), professora da rede estadual de educação do Estado da Bahia. Email: walmeria.dantas@yahoo.com.br.

**Doutora em Teorias e Críticas da Literatura e da Cultura pela Universidade Federal da Bahia. Professora Titular de Literatura Portuguesa e Brasileira da Universidade Estadual de Feira de Santana. Email: alanafreitasfahl@gmail.com. 
conceito de sequência didática, segundo Dolz, Noverraz \& Schneuwly (2004), e como esse modelo pode ser adaptado para atender em contextos diferenciados, segundo Swiderski e Costa-Hübes (2009).

Após tecermos algumas considerações sobre o Haicai, apresentamos parte do material pedagógico preparado especialmente para os sujeitos da pesquisa, tendo em vista tanto suas necessidades de aprendizagem quanto seu o contexto sócio-cultural.

A turma escolhida para a intervenção era composta de 33 alunos regularmente matriculados no $7^{\circ}$ ano $\mathrm{A}$ do ensino fundamental, no turno matutino. São 16 meninos e 17 meninas, com idades variáveis entre 11 e 13 anos. Desses, apenas um aluno era repetente do sétimo ano.

As atividades aqui apresentadas objetivaram: promover reflexões acerca das práticas de leitura dos jovens; contribuir para incentivar práticas de leituras que concorram para a sua formação autônoma e crítica; favorecer processos colaborativos de construção de sentidos e significados que propiciem o aprimoramento de capacidades básicas de leitura e de outras textos necessários à fruição de textos literários.

A necessidade de materiais didáticos que auxiliem no desenvolvimento das habilidades leitoras e ampliem o conhecimento linguístico, levando em consideração o contexto histórico e social dos alunos como ponto de partida para a aprendizagem, também serviu de motivação para o nosso trabalho.

\section{LETRAMENTO LITERÁRIO}

A leitura e a escrita são práticas culturais muito valorizadas em nossa sociedade. Há diversas atividades sociais que articulam leitura e produção de textos em contextos diversificados. Tais práticas são denominadas letramento. Conforme Soares (2001, p.16-17), letramento é a versão para o português da palavra da língua inglesa literacy, que remete à idéia de pessoas "educadas", que não apenas dominam a escrita e a leitura, mas utilizam competentemente essas ferramentas nas práticas cotidianas.

O letramento literário é singular aos demais letramentos, uma vez que se realiza a partir da literatura. Portanto, pode ser definido como "[...] o processo de apropriação da literatura enquanto construção literária de sentidos” (PAULINO; COSSON, 2009, p. 67).

Entretanto, o processo do letramento literário não é apenas um saber adquirido sobre a literatura, nem se resume a uma habilidade pronta e acabada de ler textos literários, mas envolve compreender e produzir sentidos do texto, de si próprio e do mundo. De acordo com Paulino (2010), como outros tipos de letramento, continua sendo uma " [...] apropriação pessoal de práticas sociais de leitura/escrita, que não se reduzem à escola, embora passem por ela".

Nesse sentido, Cosson (2014, p. 23) explica:

[...] devemos compreender que o letramento literário é uma prática social e, como tal, responsabilidade da escola. A questão a ser enfrentada não é se a escola deve ou não escolarizar a literatura, como bem nos alerta Magda Soares, mas sim como fazer essa escolarização sem descaracterizá-la, sem transformá-la em um simulacro de si mesma que mais nega do que confirma seu poder de humanização. 
Por meio de estratégias de leitura bem definidas, visando o letramento literário, o professor pode proporcionar o que, segundo Antônio Cândido (1995. p,112), é um direito fundamental à existência humana: o encontro do aluno com o objeto de arte literária, promovendo momentos de estranhamento e fruição. Isso pode auxiliá-lo a reconhecer os recursos estilísticos e linguísticos utilizados pelo autor e como estes contribuem para a produção dos sentidos do texto, ajudando o estudante a estabelecer relações com sua realidade.

Dessa forma, para que o nosso projeto de intervenção baseie-se nos princípios do letramento literário, utilizamos o haicai em conexão com a fotografia como gancho para o estudo do texto poético.

\section{O HAICAI: DO JAPÃO PARA AS VIVÊNCIAS NO AMBIENTE ESCOLAR}

Ao longo da história da poesia, algumas formas foram se cristalizando e permanecem até os nossos dias, como o terceto de origem japonesa, denominado no Brasil de haicai. Esse terceto é originário do tanka, forma poética que aparece a partir do século VIII, dividido em duas estrofes, a primeira de 5,7 e 5 e a outra de 7 e 7 unidades silábicas (FRANCHETI, 2007, p. 198).

Segundo Franchetti (2012), o haiku não foi diretamente transmitido do Japão para o Brasil. O mundo literário brasileiro tomou conhecimento dessa forma poética através de traduções feitas para a língua francesa. Dos EUA, obras pioneiras como The Spirit of Japonese Poety, de Yone Noguchi, de 1914, e Japonese Lyrrics, de Lafcadio Hearn, de 1915, podem ter chegado até os brasileiros de então.

Mas foi o norte-americano Erza Pound (1885 - 1972) quem influenciou autores conterrâneos, além de europeus e latino-americanos. Ele foi um dos criadores do Imagismo, que pedia poemas curtos, linguagem coloquial, versos livres e imagens que procurassem fisgar a sensibilidade do leitor.

O baiano Afrânio Peixoto (1876 - 1947), em 1919, foi o pioneiro em definir o haicai para os brasileiros, no seu livro Trovas Populares Brasileiras. Em 1928 publicou artigo sobre Haicai na revista Excelsior. E incluiu 50 haicais no seu livro Miçangas, em 1931.

Guilherme de Almeida (1890-1968), com o intuito de abrasileirar o haicai, formatou-o numa espécie de poema parnasiano. É um terceto, com título e com as sílabas métricas em 5, 7 e 5, incluindo a inovação de ter duas rimas: uma para ecoar o final do primeiro e do terceiro verso; outra dentro do segundo verso, na segunda e na última sílaba, conforme expresso em seu haicai intitulado Infância:

Gosto de amora

Comida com sol. A vida

Chama-se: agora (ALMEIDA, 1963. p. 59).

Nesta pesquisa, optou-se por essa forma poética porque, dentre outras características, além ser pequena, em extensão, seu conteúdo é facilmente associado a uma imagem (As imagens que acompanham o haicai, são denominadas haiga.). Essas duas 
características do haicai o aproximam dos textos curtos que os alunos leem e compartilham nas redes sociais. Para o trabalho de produção de haicais, primaremos pela forma livre com reflexão humorística, segundo os moldes de Millôr Fernandes em seu livro Hai-Kais (1997).

Portanto, no contexto dessa pesquisa, o haicai é tomado como gênero poético a ser transposto às aulas de língua materna, para o desenvolvimento de capacidades de linguagem, por meio da metodologia de sequência didática, considerando seu conteúdo temático, estilo e estrutura composicional, com vistas ao letramento literário dos sujeitos da pesquisa.

No contexto deste trabalho, tomamos a imagem como elemento de conexão entre os gêneros que mobilizamos em nossa sequência didática, a saber o Haicai e a Fotografia. Buscamos entender imagem conforme exposto por Octavio Paz (1990. p, 120), para quem toda imagem aproxima ou conjuga realidades opostas, indiferentes ou distanciadas entre si. Graças a uma mesma redução racional, os elementos não perdem as características que os distinguem.

Produzir imagens e compartilhá-las via internet com o auxílio de um smartphone tornou-se prática cotidiana em nossa sociedade. Sendo a escola o espaço social encarregado de desenvolver as habilidades de leitura da sua clientela com vistas à formação de um leitor crítico, ela não pode ficar alheia às práticas sociais de leitura que ocorrem fora dela.

O entendimento de imagem fotográfica como mediação entre o homem e o mundo perpassa pela questão da afetividade que envolve as relações entre o olhar de quem fotografa, o objeto fotografado e o olhar de quem observa a fotografia. Considerando esses aspectos, encontramos em Brathes (1984) caminhos para reflexão.

Barthes (1984, p. 84-85) destaca alguns conceitos importantes na ação de fotografar: o operator, o spectator e o spectrum. O primeiro é uma referência ao fotógrafo em si, o spectator é o público a quem são dadas a observar as fotografias, e o spectrum da fotografia é o ser fotografado, o referente, ou, como ele explica, "o espetáculo que se oferece ao olhar". Estes três conceitos surgem associados às práticas do fazer, olhar e experimentar.

Assim, partindo dos conceitos de Barthes, estabelecemos as seguintes relações: o operator (o fotógrafo/haicaísta) tira a foto/escreve o poema de acordo com seu foco/kigo escolhido, e o spectator (leitor) olha a foto/haicai, o referente (spectrum), no seu todo (studium), conjuntura que possibilita perceber as intenções do operator no instante em que eterniza a imagem. No entanto, um spectator crítico procura o punctum, ou seja, os detalhes que o impressionam, o pormenor que salta da cena.

O poeta nos apresenta a fotografia como expressão que mobiliza os nossos afetos. Nesse sentido, observamos outra conexão com o haicai, que por meio de imagens criadas com recursos da linguagem literária também é passivo de mobilizar afetos.

Neste trabalho, propusemos aos sujeitos participantes experimentarem o fazer do fotógrafo e do poeta, comungando ambos a escrita de haicais ilustrados por fotografias, que narrassem instantes contemplados das vivências no ambiente escolar. 


\section{A SEQUÊNCIA DIDÁTICA E A UTILIZAÇÃO DO MATERIAL DIDÁTICO}

Um dos objetivos pretendidos pela escola é possibilitar que os alunos desenvolvam competências que lhes permitam ler e produzir textos orais e escritos de diferentes gêneros.

Visto que os textos se organizam dentro de "certas restrições de natureza temática, composicional e estilística, que os caracterizam como pertencentes a este ou aquele gênero" (BRASIL, 1998, p. 23), a noção de gênero precisa ser tomada como objeto de ensino.

Essa posição defendida pelos PCN ancora-se nos estudos de Mikhail Bakhtin (1895-1975). O autor reforça a importância do trabalho com gêneros ao dizer:

Quanto melhor dominamos os gêneros tanto mais livremente os empregamos, tanto mais
plena e nitidamente descobrimos neles a nossa individualidade (onde isso é possível e
necessário), refletimos de modo mais flexível e sutil a situação singular da comunicação; em
suma, realizamos de modo mais acabado o nosso livre projeto de discurso. (BAKHTIN,
2003, p. 285)

Compreendemos que a sequência didática, orientação teórico-metodológica concebida na Unidade de Didática de Línguas, na Universidade de Genebra, a partir de 1985, e desenvolvida principalmente pelos pesquisadores Dolz, Noverraz e Schneuwly (2004), na Suíça, baseada nos conceitos bahktinianos, direciona um trabalho que favorece a promoção dos alunos ao domínio dos gêneros e das situações de comunicação (DOLZ; NOVERRAZ; SCHENEUWLY, 2004, p. 97).

De acordo com os pesquisadores supracitados, sequência didática é um conjunto de atividades escolares organizadas, de maneira sistemática, em torno de um gênero textual oral ou escrito (Dolz, Noverraz e Schneuwly, 2004, p. 97). Na imagem a seguir, apresentamos o modelo de Sequência Didática (SD) criado por eles:

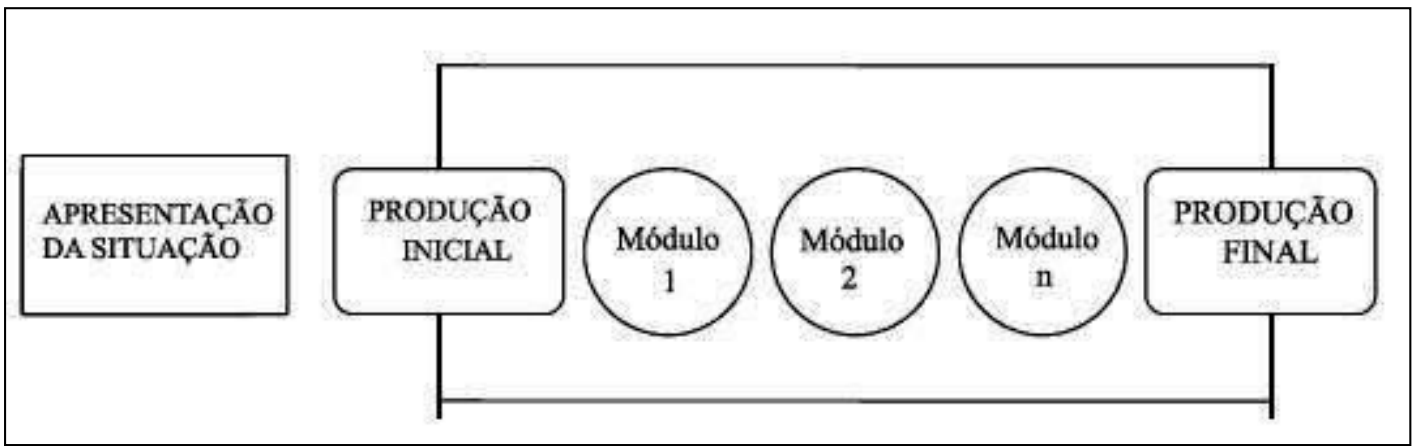

Figura 1 - Esquema de SD de Dolz; Noverraz; Schneuwly (2004)

Fonte: (DOLZ; NOVERRAZ; SCHNEUWLY, 2004, p. 98).

Sobre a importância da elaboração de uma SD, Araújo (2013, p. 324-325) considera:

[...] a ideia central de uma SD é a didatização de um gênero cuja produção é processualmente 
elaborada. Embora, tal conceito tenha sido, em princípio, apresentado para o ensino de escrita, pode e deve ser empregada para o ensino de leitura e de análise linguística. Acreditamos que ensino de um gênero, seja escrito ou oral, implica na realização de procedimentos, atividades e exercícios sistemáticos que envolvem esses três componentes do ensino de língua: leitura, análise linguística e produção.

Assim, ao proceder à didatização do gênero, é importante que o professor tenha consciência de que, em uma SD, não é necessário abranger todas as dimensões ensináveis do gênero em si. Dolz, Noverraz e Schneuwly (2004) orientam um trabalho de apropriação da linguagem em "espiral". Isso significa que o trabalho deve ser planejado de acordo com o nível dos alunos, entendendo que o mesmo gênero pode ser retomado em etapas seguintes.

A partir da proposta de SD dos pesquisadores de Genebra, Dolz, Noverraz e Schneuwly (2004), Costa-Hübes (2008; 2007) procurara adaptá-la à realidade dos anos iniciais do Ensino Fundamental brasileiro. Segundo Swiderski e Costa-Hübes (2009), a proposta de adaptação prevê como anterior à etapa de produção inicial a necessidade de inserção de um módulo de reconhecimento do gênero, com atividades de leitura, pesquisa e análise linguística com textos do gênero, conforme podemos observar na figura a seguir:

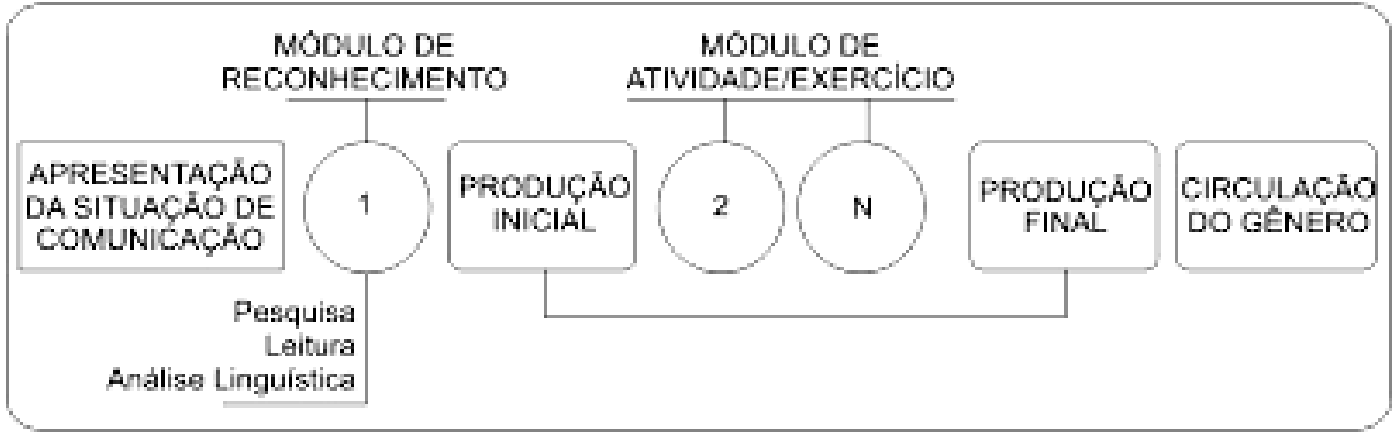

Figura 2 - Esquema de SD de Swiderski e Costa-Hübes (2009)

Fonte: Swiderski e Costa-Hübes (2009).

Com base em Dolz; Noverraz e Chneuwly (2003) e Swiderski e Costa-Hubes (2009), à nossa SD de leitura e escrita de haicais inspirados em fotografias acrescentamos as etapas de Sondagem, Apresentação do Gênero e Reconhecimento do Gênero, reunidas no que chamamos de Módulo preparatório, disposto antes da realização da etapa diagnóstica. Também foi necessário organizar a etapa da Circulação do Gênero, a qual chamaremos de Culminância, por se tratar de um momento festivo que marca o encerramento das atividades e a apresentação do produto final.

Com o objetivo de atendermos às necessidades dos nossos alunos, considerando o contexto sócio-cultural em que se encontram inseridos, optamos por um modelo adaptado de Sequência Didática. Nossas ações foram organizadas conforme ilustra a figura seguinte: 


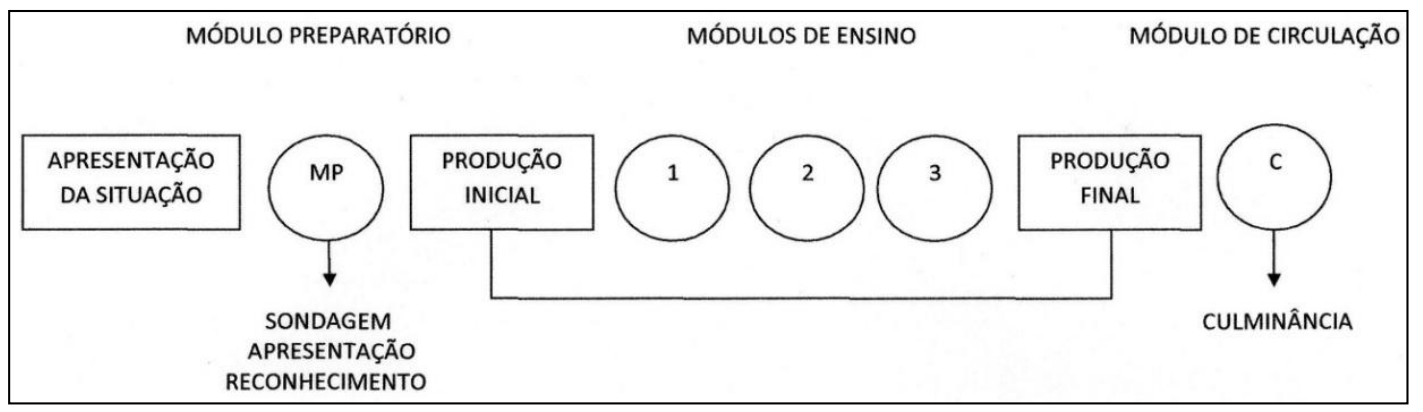

Figura 3 - Esquema da SD de haicais e fotografias

Fonte: Elaborado pelas autoras.

O material didático produzido especificamente para dar suporte às nossas atividades de leitura e produção de haicais, inspirados em fotografias autorais, tem como base as orientações contidas nos PCN (1998) e no Plano Nacional do Livro Didático - PNLD 2017. Seu layout foi ganhando forma durante as oficinas de Publisher, oferecidas pelo Prof. Dr. Patrício Nunes Barreiros, em sua disciplina Produção de Material didático para o ensino de Lingua Portuguesa, no ProfLetras/UEFS. Foi a primeira vez que tive contato com o programa Publisher, muito diferente do Word, o qual eu estava habituada a utilizar para produzir as atividades para os meus alunos. Foi desafiador explorar as possibilidades desse programa, senti dificuldades que foram superadas através da mediação do professor.

O resultado foi um módulo de aparência atraente, que procurou abordar o estudo do gênero Haicai, segundo a metodologia de SD, dentro de uma perspectiva que considera a realidade histórica e sociocultural dos nossos alunos.

\section{APRESENTAÇÃO DO MÓDULO PREPARATÓRIO PARA O ESTUDO DO HAICAI}

Neste módulo, foram desenvolvidas as etapas que julgamos necessárias para auxiliar os alunos na construção de conhecimentos básicos para se envolverem no estudo do gênero e arriscarem fazer uma primeira produção escrita. Este módulo é composto pelas atividades de sondagem, apresentação e reconhecimento do gênero, descritas a seguir:

\subsection{SONDAGEM}

A Sondagem é um procedimento de pesquisa de base etnográfica. Seu objetivo é fazer um levantamento do contexto sociocultural dos estudantes, observando suas relações com a cultura escrita. Faz-se necessário sondar o histórico dos alunos na escola com o objetivo de compreender suas relações com a aprendizagem e identificar as reais necessidades de trabalhar com o gênero escolhido. É extremamente importante conhecer os estudantes e o contexto onde a sequência didática será aplicada.

Ser professora da turma mostrou-se um fator positivo para a realização da etapa de Sondagem. Pois, possibilitou-me estabelecer vínculos de amizade e confiança, que os ajudaram a se sentirem à vontade para falarem de si e de sua relação com a leitura. 
Além de professora da turma, resido no mesmo bairro que alguns de meus alunos, conheço seus familiares e um pouco do contexto sociocultural deles. Entretanto, de outros, faltava-me esse conhecimento, que fui buscar nas consultas aos documentos da escola, como, por exemplo, na pasta do aluno, na qual conheci os nomes e as profissões de seus pais; a localidade em que residiam; em que escola haviam estudado anteriormente e se já tinham repetido alguma série. Essas informações foram levadas em consideração no momento de eleger um tema para o projeto e de pensar atividades contextualizadas e significativas para a turma.

A pesquisa na pasta do aluno revelou que alguns estudantes residiam nas proximidades da Lagoa do Novo Horizonte, região estigmatizada pela pobreza e violência. Essa constatação somada às observações das situações da sala de aula evidenciou que alguns alunos eram alvo de bullying e, consequentemente, sentiam-se constrangidos em revelar onde residiam. Sem adentrar diretamente no discurso antibullyig, pensei em como desconstruir o estigma de desvalorização apoiando-me na literatura, especialmente na poesia, como melhor explicarei na Apresentação do Gênero.

Nesta etapa de sondagem, também realizou-se conversas informais e entrevistas com os sujeitos para conhecermos suas práticas de leitura. Essas ações vieram confirmar o que já observávamos. Conforme mostrado no Gráfico 1, os alunos praticavam com mais frequência leituras de mensagens eletrônicas, compartilhadas nas redes sociais das quais fazem parte; em segundo lugar, o que mais liam eram os livros didáticos, porque, como esclareceram durante nossas conversas, precisavam lê-los para responder às atividades que os professores passam. Apenas quatro alunos informaram ler poemas frequentemente.

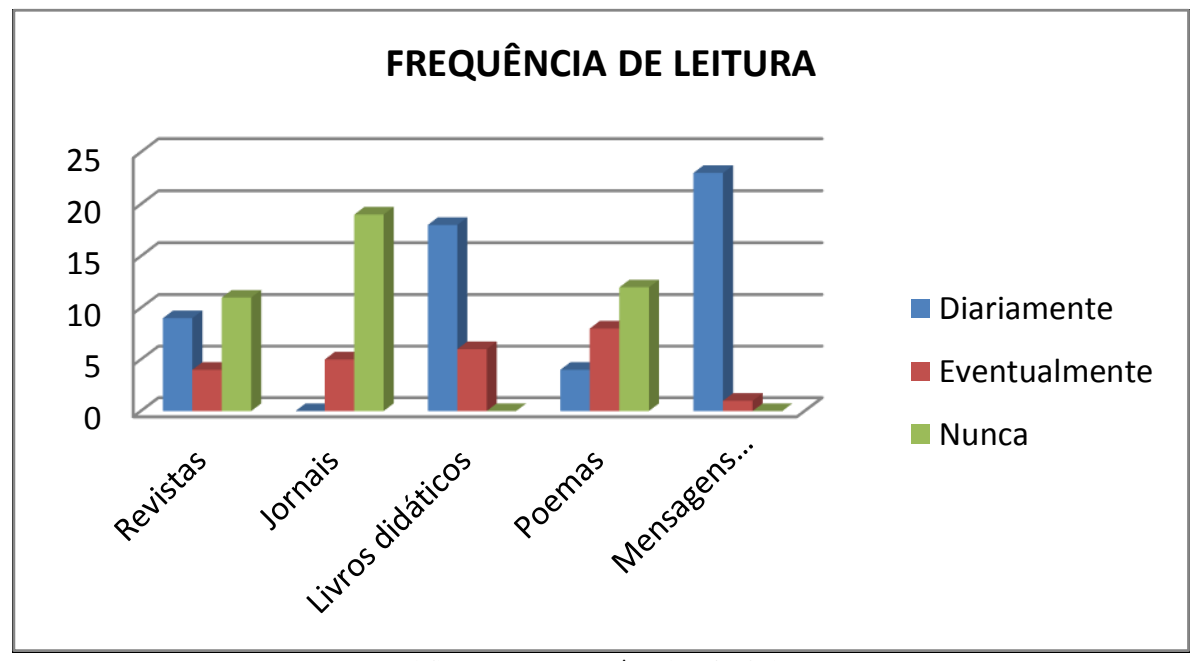

Gráfico1 - Frequência de leitura

Fonte: Elaborado pela pesquisadora.

O gráfico dois mostra que música, esporte e aventura são os assuntos preferidos entre os sujeitos da pesquisa. No quesito música, estão incluídas as notícias sobre os astros musicais preferidos dos entrevistados. Eles revelaram, em nossa conversa informal, que 
gostam de ficar informados sobre o que acontece com seus artistas favoritos. O esporte ocupou o segundo lugar, $21 \%$ da turma gosta de ler matérias sobre o time de futebol para o qual torcem. Na categoria Aventura, estão compreendidas as histórias de ficção, romances, contos, crônicas, poemas etc. A sondagem revelou que esse também é um tipo de texto que agrada aos alunos. $\mathrm{Na}$ categoria Outros, as mensagens de texto compartilhadas em redes sociais por meio da internet foram as mais citadas pelos sujeitos.

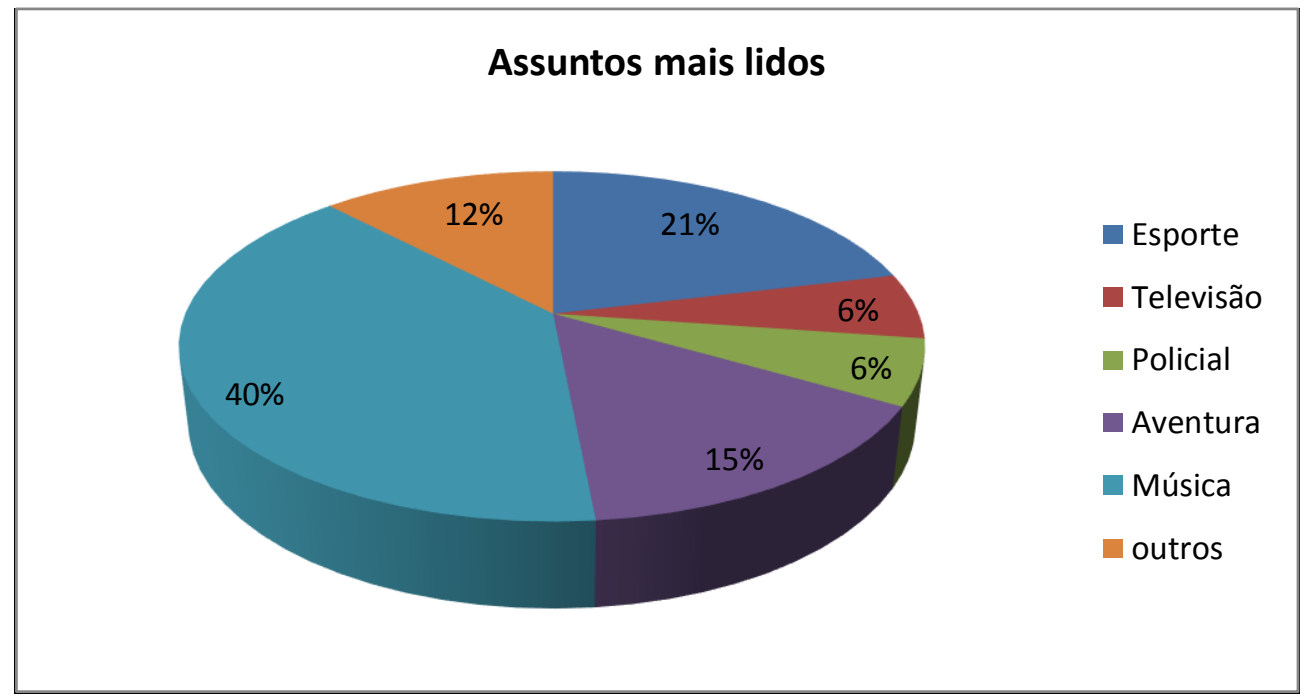

Gráfico 2 - Assuntos mais lidos pelos sujeitos

Fonte: Elaborado pela pesquisadora

Os percentuais do gráfico seguinte confirmam uma realidade observável no dia a dia dos sujeitos: a de que eles leem com frequência os textos compartilhados em ambientes virtuais e, para tanto, utilizam seus equipamentos eletrônicos, smartphone, tablet etc.

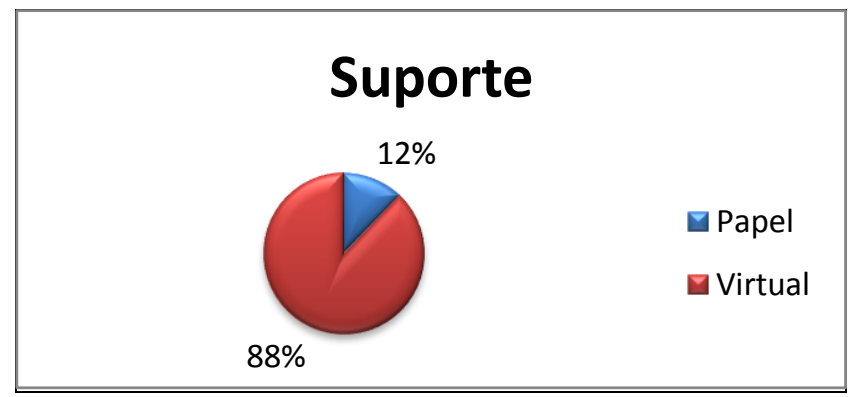

Gráfico 3 - Suporte mais utilizado para leitura

Fonte: Elaborado pela pesquisadora.

No que diz respeito à leitura de livros da esfera literária, os de contos, romances e poemas, os sujeitos revelaram que enfrentam dificuldades para se dedicarem a essa prática. $27 \%$ informaram que se sentem sobrecarregados com tantas atividades de classe e extraclasse e que, por isso, não têm tempo para lerem livros que não sejam os didáticos. 
As maiores dificuldades informadas são as mostradas no gráfico a seguir:

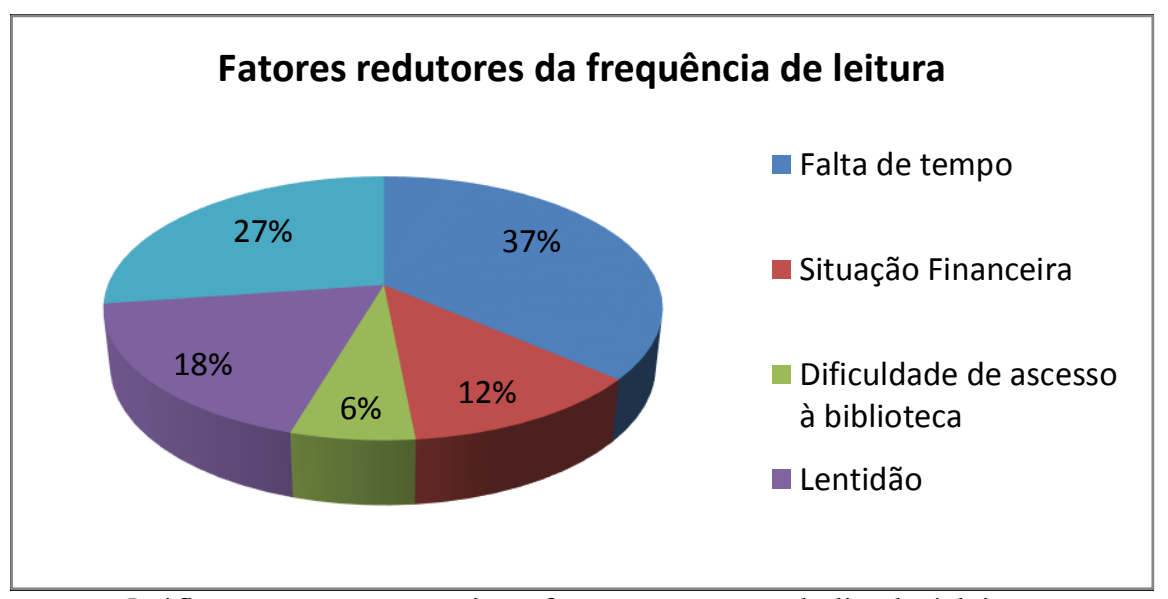

Gráfico 4 - Fatores que interferem no tempo dedicado à leitura Fonte: Elaborado pela pesquisadora

A questão do gostar ou não de ler foi levantada no início da nossa conversa, quando $99 \%$ dos sujeitos responderam que não gostavam de ler, pois compreenderam leitura como atividade puramente escolar e imposta pelos professores, a qual realizavam a contragosto, com o propósito de obterem média suficiente para aprovação. Após lermos alguns textos e refletirmos sobre as práticas sociais de leitura nas quais eles também estão inseridos, retomamos o questionamento inicial e a resposta passou a ser positiva. Os sujeitos compreenderam que liam bastante e que, inclusive, gostavam de ler principalmente textos acompanhados de imagens, os quais pudessem ser compartilhados nas redes sociais. Essa compreensão justifica os dados mostrados no gráfico a seguir:

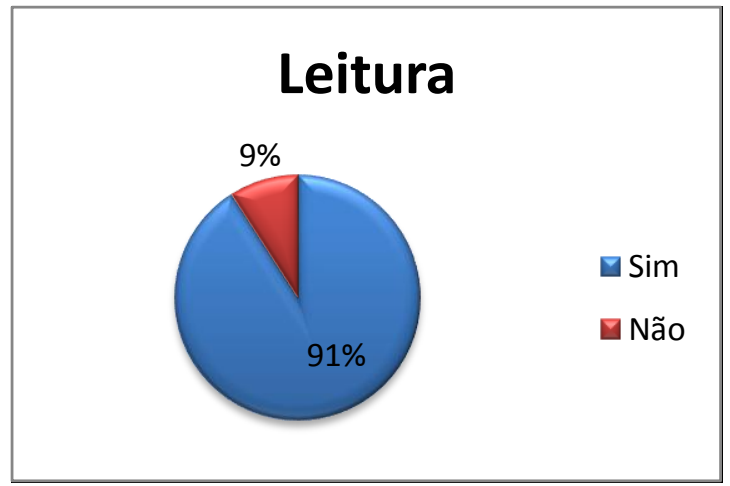

Gráfico 5 - Você gosta de ler?

Fonte: Elaborado pela pesquisadora.

A sondagem revelou que os sujeitos entrevistados leem e escrevem bastante nas plataformas virtuais que utilizam com certa frequência, mas demonstram um desinteresse 
generalizado pelos textos da esfera literária, que são instrumentos para leitura e aprendizagem nas escolas. Isso evidencia a necessidade de uma intervenção com objetivo de motivá-los a desenvolverem gosto, encantamento e paixão pela leitura de textos literários, a começar pelo poema.

\subsection{APRESENTAÇÃO DO GÊNERO}

A etapa de Apresentação do Gênero é desenvolvida com base nos dados obtidos na Sondagem. O objetivo desta etapa é demonstrar para os alunos que o gênero estudado está integrado ao meio social circundante.

No período programado para a realização do nosso projeto, toda a comunidade escolar, inclusive nós, participaria do Projeto Água, estudo interdisciplinar sobre o meio ambiente, focado nos recursos hídricos de Feira de Santana. Coube ao nosso sétimo ano a pesquisa sobre as lagoas feirenses. Considerando a necessidade de desconstruir o estigma de inferioridade que acometia alguns dos alunos que residem nas proximidades da Lagoa do Novo Horizonte com relação aos que residem nas imediações do Colégio Estadual José Ferreira Pinto, selecionei diferentes gêneros de textos sobre o tema das lagoas feirenses, para discutir e refletir a importância desses ecossistemas, focalizando os estudos de leitura e linguagem do gênero Haicai.

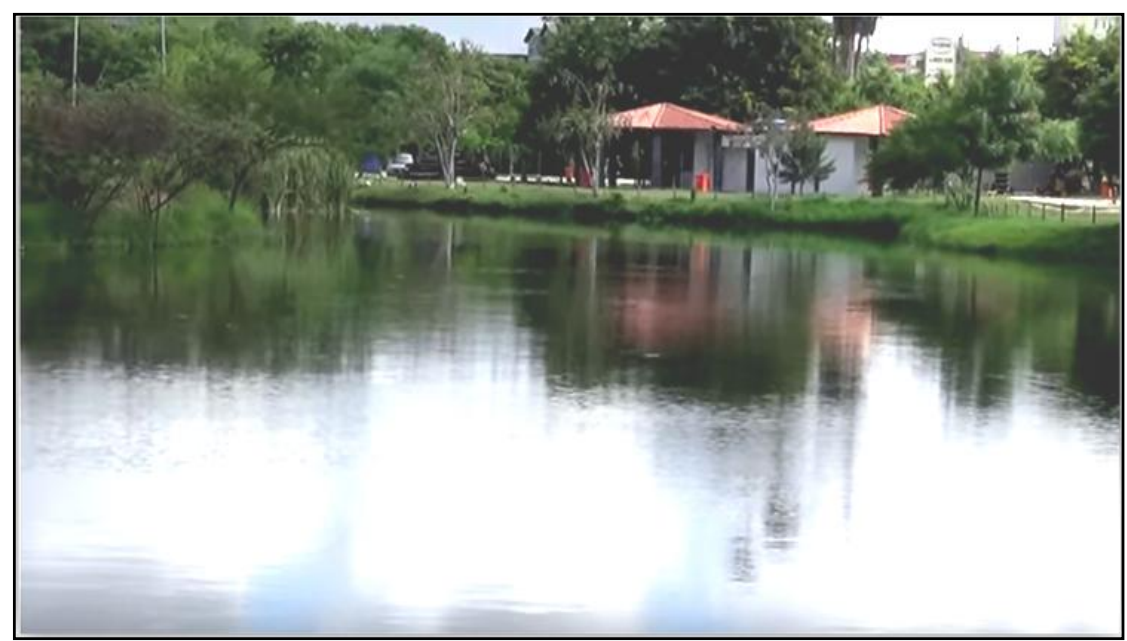

Figura 4 - Lagoa do Prato Raso, em Feira de Santana - BA

Fonte: <http://feirenses.com/lagoas-feira-de-santana>

Eu acreditava que todos os alunos conheciam aquela lagoa, pelo fato dela estar localizada nas margens de uma das principais vias que dá acesso ao centro da cidade, na Avenida José Falcão. Entretanto, minhas suposições não foram confirmadas. A conversa motivada pela observação da imagem fotográfica da Lagoa do Prato Raso revelou que eu estava enganada. (PESQUISADORA).

A partir da imagem fotográfica apresentada, surgiram comentários relacionados aos cuidados com o meio ambiente. Conforme a fala de A3: 
A3: Lá no Parque da Lagoa tem vários brinquedos, eu fui com meus primos e meu pai, lá é tudo limpo, tem guardas que tomam conta do lugar, ninguém pode jogar lixo no chão! Quando eu fui, vi muitas pessoas tirando foto, as pessoas gostam de tirar foto lá porque é bonito, tem a natureza e muitos animais!

Os alunos receberam os módulos de atividades e foi-lhes pedido que, em pares, conversassem entre si, conforme às indagações propostas, e anotassem o que achassem importante para ser dito no momento de socialização das opiniões. Os questionamentos propostos para o diálogo sobre a imagem em questão eram os seguintes:

- Que elemento está em primeiro plano na fotografia?

- Você sabe em que lugar essa fotografia foi tirada? Você já foi a esse lugar?

- Você considera importante preservar as lagoas da sua cidade? Por quê?

- A fotografia acima pode, ou não, ser considerada arte? Por quê?

Quando abrimos para a socialização, alguns alunos ficaram tímidos, não quiseram falar, enquanto outros não queriam parar de falar. Os que puderam se expressar disseram que achavam importante conhecer mais sobre as lagoas porque isso podia ajudar a preservá-las. Quanto ao último questionamento, os alunos de imediato disseram que sim, que fotografia também é uma forma de arte.

Em um segundo momento fizemos a leitura de três poemas de forma e autores diferentes, mas tendo um tema em comum, a saber, água/lagoa. O primeiro a ser lido foi o poema Lagoa, de Drummond; o segundo foi Poesia, de Aleilton Fonseca, e o terceiro foi o "Haicai da rã" (assim referido por não possuir título), de Bashô (Figura 5).

Após a leitura dos três textos, falamos sobre seus respectivos autores, para tanto, utilizamos o quadro Quem é? localizado ao lado de cada poema. Falamos brevemente sobre o contexto histórico e cultural de produção de cada um dos poemas lidos. Falamos sobre as imagens criadas por cada um deles, tentando, na medida do possível, relacioná-las com a nossa realidade. Essa conversa foi positiva, pois deixou os alunos mais motivados e interessados em participar das atividades.

Levei Poesia, de Aleilton Fonseca, com uma certa insegurança, considerava a possibilidade dos alunos o rejeitarem por acharem difícil, ou seja, por não conseguirem atribuir sentidos à sua leitura. Mas, outra vez, fui surpreendida., Alguns comentários sobre a diferença entre poema e poesia, embasados nesse poema, mostraram-se de uma enorme sensibilidade e compreensão de imagens, como, por exemplo, o comentário registrado a seguir sobre a leitura do verso " ...a poesia: o rosto na água;/o poema, sua inconstante/aparência, forma mutante, ..." :

A3: A poesia representa sentimentos, ela pode nos tocar assim como a água que toca nosso rosto. Dependendo do momento isso pode ser bom ou pode ser ruim. O poema é o texto, uns tem rima outros não tem e eles também tem formas e tamanhos diferentes, como esses que nós lemos. 


\section{TEXTO 2}

\section{POESIA}

$[\ldots]$

24

a poesia: o rosto na água;

o poema, sua inconstante

aparência, forma mutante,

em recorrência, minúsculas

mudanças em contínua

ação

28

mas não há a poesia finita,

mas corrente, em espiral, sem termo

o poema é o instante,

dessa corrente em passagem

re-fulminante,

diante dos olhos atônitos

do poeta, às vezes surpreso,

em agônico gesto

[...]

FONSECA, Aleilton. Poesia. Disponivel em $<\mathrm{http}: /$ aleilton.blogspot.com.br/p/poesia.html $>$ Acesso em: $30 / 04 / 16$

\section{TEXTO 3}

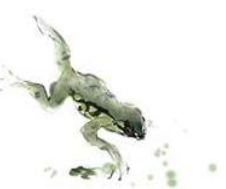

velha lagoa

uma rã pula

o som da água

BASHÔ, Matsuo. Trilha estreita ao confim.Trad.: TAKENAKA, Kimi; MARSICANO, Alberto. São Paulo: Iluminuras, 1997. p. 12 .

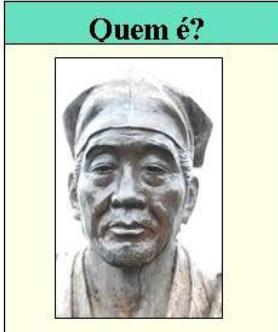

Matsuo Bashō, ou simplesmente Bashō, foi o poeta mais famoso do período Edo no Japão. Durante sua vida, Bashô foi reconhecido por seus trabalhos colaborando com a forma haikai no renga. (1644 - 1694)

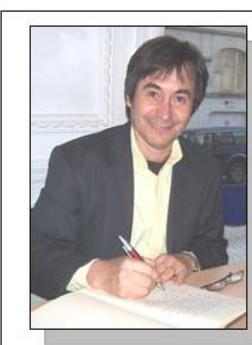

Quem é?

\section{ALEILTON FONSECA}

Nascido em Itamirim, hoje Firmino Alves - Bahia, em 21/07/1959. É casado e tem 2 filhos. E poeta, ficcionista, ensaísta e professor da UEFS. Desde 2005, pertence à Academia de Letras da Bahia, ocupando a cadeira $n^{\circ} 20$. Saiba mais sobre o artista, visitando o site:

$<$ http://aleilton.blogspot.com.br/p/biografia.html >

Figura 5- Apresentação do gênero

Fonte: http://www.youblisher.com/p/1912898-Sequencia-didatica-de-haicais/

$\mathrm{Na}$ sequência, assistimos a um vídeo que apresentava uma vista aérea da Lagoa do Prato Raso, nosso objetivo foi o de identificar, nas imagens, elementos que pudessem servir de inspiração para a criação de poemas. Os alunos apontaram vários elementos, dentre os quais: a água, os animais, as árvores, o céu, as crianças etc. Pedi que retornassem ao módulo e olhassem a foto da Lagoa do Prato Raso, eles rapidamente o fizeram. Depois solicitei que acompanhassem a leitura do quadro: "A captura do momento", na página 7 do módulo (Figura 6). Finalmente, indaguei: Qual dos poemas lidos no módulo parece pintar (ou fotografar) uma cena no momento em que ela acontece? "O da rã", responderam.

Então, perguntei se eles já tinham lido poemas com essa forma e linguagem tão sintética. As respostas variaram entre sim e não. Alguns alunos reconheceram de imediato. A9 disse que era um haicai e que possuía um livro de haicais que ganhara da madrinha. Confirmei que se tratava de um haicai e mostrei alguns dos livros cuja leitura faríamos no decorrer do projeto, a saber, O pequeno livro de Hai-Kais do Menino Maluquinho, de Ziraldo (2013), e Hai-kais, de Millôr Fernandes (2014), dentre outros. 
Permiti que pegassem, folheassem e levassem emprestado para lerem com alguém em casa. Os alunos acolheram, com satisfação, os livros e a ideia de levá-los para casa. Como não havia volumes suficientes para todos, propusemos um sistema de rodízio, em que cada aluno ficaria dois dias com um livro e o devolveria para ser emprestado novamente, até que todos na turma tivessem lido todos os exemplares.

Reservamos um momento para a leitura da crônica O Divino Bashô, de Cecília Meireles (1901-1964). Essa leitura permitiu aos alunos compreenderem um pouco da origem, da temática e da linguagem empregada no Haicai. Além de conhecerem a filosofia de vida de Matsuo Bashô (1644-1694), o maior representante japonês desse gênero. Essa leitura também serviu de gancho para a etapa de Reconhecimento do gênero.

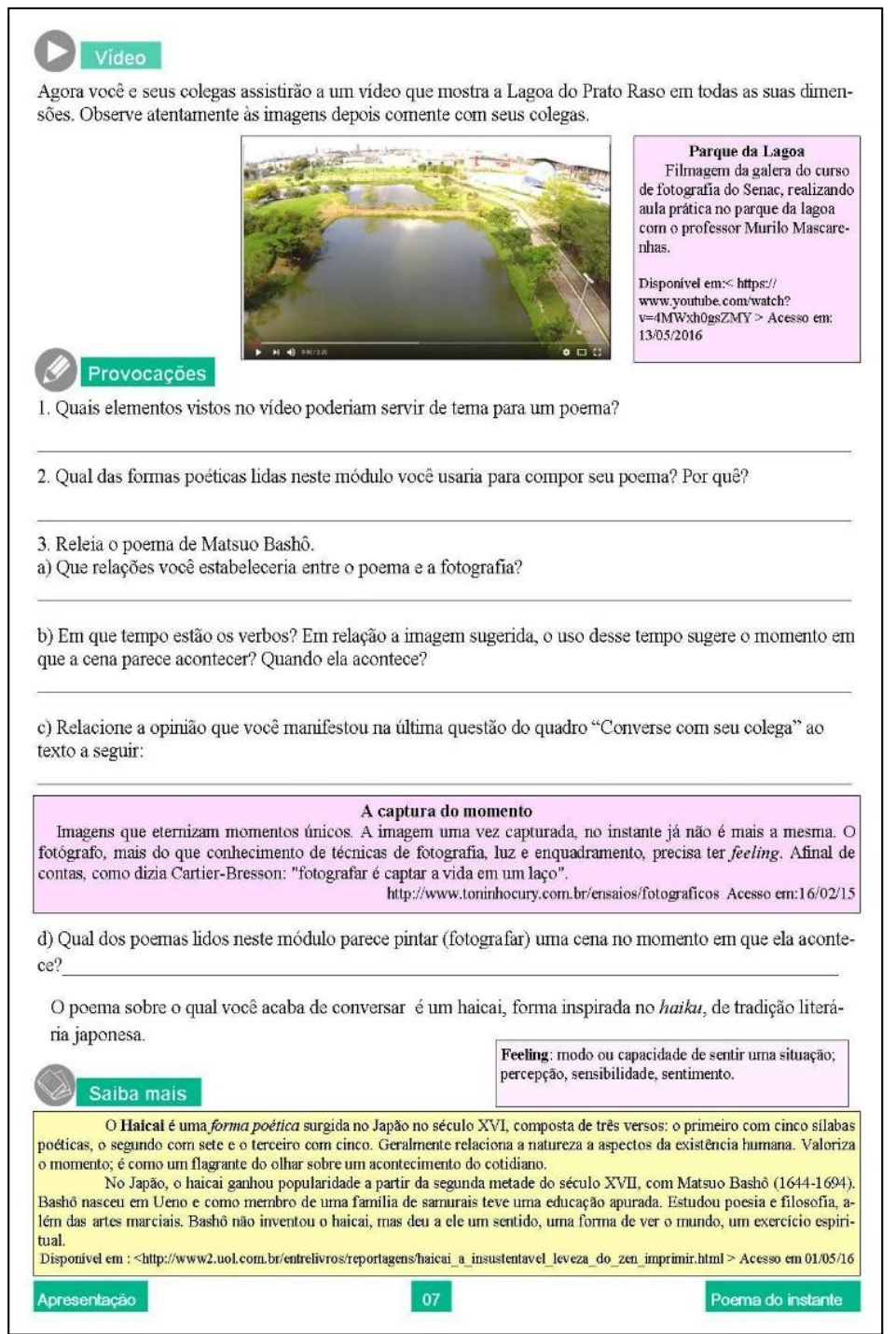

Figura 6 - A captura do momento

Fonte: http://www.youblisher.com/p/1912898-Sequencia-didatica-de-haicais/ 


\subsection{RECONHECIMENTO DO GÊNERO}

Essa etapa tem por objetivo dar aos alunos condições para produzirem o primeiro texto. As atividades são focadas nas funções sociais do gênero, nos diferentes contextos de produção, sua estrutura organizacional e suas marcas linguísticas. É fundamental que, ao fim das atividades dessa etapa, o aluno seja capaz de compreender a função social do haicai, reconhecê-lo em suas diferentes formas de materialização e contextos, bem como identificar as impressões características de sua linguagem.

Nesta etapa, os alunos puderam expressar seus conhecimentos acerca da cultura popular japonesa e como alguns elementos dessa chegam até nós e são incorporados pela nossa cultura. No intuito de motivar esse diálogo, levei para a sala a imagem de um cartaz do guia para mangás, o JAPOP (Figura 7). De imediato, os alunos reconheceram seus personagens prediletos e outros, não tão queridos. Sentados em dupla, eles consideraram as perguntas do boxe "Converse com seu colega". Uma das perguntas desse boxe era: "Você lembra os nomes da arte e do artista japonês mencionados na crônica de Cecília Meireles, que lemos no nosso último encontro?". Uns poucos hesitaram em responder e preferiram o silêncio. A maioria falou ao mesmo tempo. Pedi que apenas um deles falasse e indiquei qual seria. A4 respondeu: "A arte é Haicai e o artista é Matsuô Bashô". Perguntei se a turma concordava e a resposta unânime foi que sim.

Conscientes de que a aprendizagem envolve leitura e pesquisa, planejamos nossa ida à biblioteca da escola para pesquisarmos a história do Haicai e de seu maior representante japonês, Matsuô Bashô, e como essa forma poética chegou ao Brasil. Para tanto, os alunos consultaram enciclopédias e livros de poemas. Leram vários poemas de Guilherme de Almeida, contidos em exemplares de uma coleção do Programa Nacional Biblioteca da Escola (PNBE). Nessa ocasião, aproveitamos para anotar em nossas cadernetas os haicais preferidos.

Uma atividade desta etapa, que deixou os alunos empolgados, foi a leitura d'O pequeno livro de Hai-Kais do Menino Maluquinho, de Ziraldo (2013). Apresentei o livro em suporte de papel para a turma, deixei que os estudantes o pegassem, olhassem de perto, sentissem a textura do papel e o cheirinho de livro novo (pois eu havia levado alguns exemplares ainda no plástico, conforme embalados pela editora). Nesse primeiro momento, a leitura foi oralizada pela professora. Depois apresentei para eles a versão virtual, em formato e-book, do referido livro. Expus em data show e mostrei como manejar esse formato de livro. Sugeri que fizéssemos uma leitura coletiva dos haicais. Por fim, comentamos as imagens, falamos sobre o autor e sugeri um site para uma pesquisa mais detalhada sobre o desenhista e escritor, Ziraldo.

Em outro momento, os alunos experimentaram estabelecer relações de proximidade de sentidos entre as imagens produzidas por meio dos textos verbais (os haicais) lidos e as imagens produzidas por meio dos textos não verbais (as fotografias). Para tanto, foi necessário mediação, principalmente para ler as fotografias.

No final desta etapa, eles demonstraram algumas habilidades para a leitura de haicai e de fotografias. Por meio do desempenho nas atividades e dos comentários de alguns deles, percebi que compreenderam a função social do haicai e da fotografia, como 
observado nos comentários:

A10: Foi divertido ler os Hai-kais do Menino Maluquinho!

A5: Haicai é poesia e fotografia também pode ter poesia.

A15: O haicai e a fotografia servem para a gente expressar de forma poética alguns momentos que queremos guardar para sempre.

A9: Eu já gostava de tirar fotos, agora vou tirar fotos e escrever haicai, é legal!

A8: Antes eu achava que todo poema composto só de três versos era um Haicai, agora eu sei que não é só isso, que tem outras coisas, como o tema e a linguagem.

Esses comentários evidenciam que houve alguma compreensão, por parte dos alunos, das características principais do gênero, seu modo de produção, circulação e função social. Tais conhecimentos foram postos em uso no módulo de Produção Inicial e aprimorados no módulo de Produção Final. O material didático criado originalmente para essa pesquisa pode ser acessado no seguinte endereço eletrônico: http://www.youblisher.com/p/1912898-Sequencia-didatica-de-haicais/. 


\section{O Haicai: do Japão para o Brasil FLAHS POÉTICO

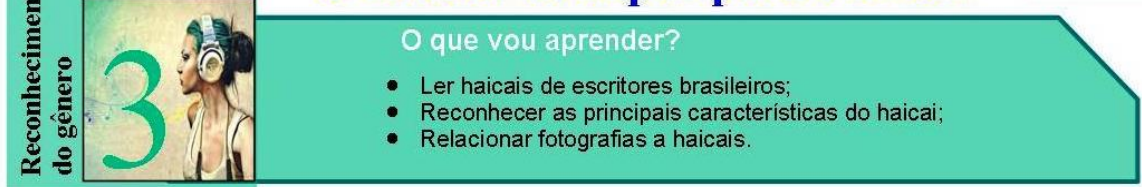

\section{Provocação}

1. Observe atentamente o cartaz abaixo e converse com seu colega:

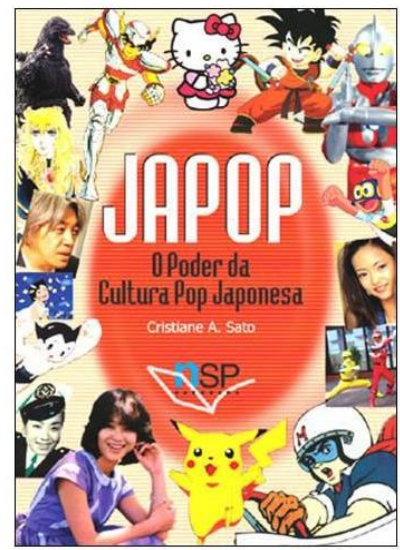

JAPOP - O Poder da Cultura Pop Japonesa é um guia para o intrincado meio dos mangás, dos animês e aos complexos traços da história e da cultura tradicional refletidos em formas de expressão cultural populares contemporâneas, como karaokê, a dança Yosakoi Soran, o teatro

Takarazuka e a própria moda japonesa.

Detalhado e surpreendente retrato do Japão contemporâneo, JAPOP revela como a sociedade

japonesa foi capaz de se tornar uma das nações mais industrializadas do planeta preservando suas raizes, tornando-se exemplo imitado por uma geração jovem, urbana, globalizada e multimidia em todo o mundo. Saiba mais no site: $h t t p: / / w w w . j o p o p . c o m . b r /$

Disponivel em: $<$ http: $/ / w w w . j a p o p . c o m . b r$ $>$ Acesso em: 04/05/16

\section{Converse com seu colega:}

- $\quad$ O que você sabe sobre o Japão? Conhece alguma arte ou artista japonês? Qual?

- Quais elementos provenientes da cultura japonesa você gosta?

- Você lembra os nomes da arte e do artista japonês mencionados no texto de Cecília Meireles, que lemos no nosso último encontro?

\section{Leitura}

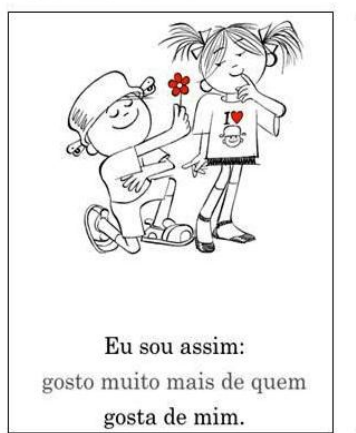

Aluno(a):

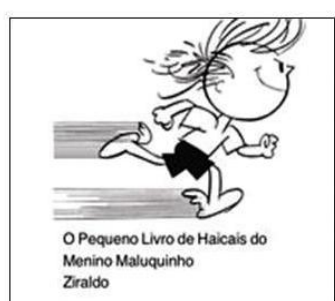

Primeiro, eu tento. Se o vento não ventar, eu invento!
1. Você conhece esses personagens? Sabe quem os criou?

2. E os textos? Você sabe que tipo de textos são esses? E quais são as características desse tipo de texto?

\section{Reconhecimento}

Série: $7^{\circ}$ ano $\mathrm{A}$

Figura 7: Reconhecimento do gênero

Fonte: http://www.youblisher.com/p/1912898-Sequencia-didatica-de-haicais/ 


\section{CONSIDERAÇÕES FINAIS}

Os resultados obtidos nesta etapa da pesquisa indicaram que o contato dos alunos com o material cuja preparação foi feita pensando na realidade e nas necessidades deles gerou receptividade, o que interferiu de modo positivo na realização das sequências de atividades propostas e, consequentemente, na aprendizagem.

Embora o material didático utilizado nesta pesquisa de intervenção tenha sido pensado para uma turma em especial, o nosso desejo é que esse material também possa ser acessado e adaptado para servir a outras turmas. Em posterior artigo, abordaremos as produções iniciais e finais dos alunos e a análise dos dados obtidos com a intervenção.

\section{REFERÊNCIAS}

ARAÚJO, D. O que é (e como far) sequência didática? Entrepalavras, Fortaleza, ano 3, v.3, n.1, p. 322-334, jan/jul 2013.

BAKTHIN, Mikhail. Estética da criação verbal. Trad. Maria Ermantina G. G. Pereira. 2 ed. São Paulo: Martins Fontes, 2003.

BARTHES, Roland. A Câmera Clara: nota sobre a fotografia. Tradução de Júlio Casteñon Guimarães. Rio de Janeiro: Nova Fronteira,1984

BRASIL. Secretaria de Educação Fundamental. Parâmetros curriculares nacionais : terceiro e quarto ciclos do ensino fundamental: língua portuguesa/ Secretaria de Educação Fundamental. Brasília : MEC/SEF, 1998.

CÂNDIDO, Antônio. O direito à literatura. In: Vários Escritos. 3. ed. São Paulo: Duas Cidades, 1995.

COSSON, Rildo. Letramento literário: educação para vida. Vida e Educação, Fortaleza, v. 10, p. 14-16, 2006.

Letramento literário: teoria e prática. São Paulo: Editora Contexto, 2014.

DOLZ, Joaquim; SCHNEUWLY, Bernard e colaboradores. Gêneros orais e escritos na escola. Trad. E Org. de Roxane Rojo e Glaís Sales Cordeiro. Campinas, SP: Mercado das Letras, 2004.

FRANCHETTI, Paulo (org); DOI, Elza Taeko. Haikai - Antologia e História. Campinas: Ed. Unicamp, 2012.

PAZ, Octavio. O arco e a lira. Tradução de Olga Savary. Rio de Janeiro: Nova Fronteira, 1982. (Coleção Logos).

SOARES, Magda Becker. Letramento: um tema em três gêneros. 2. ed., 5. reimpressão, Belo Horizonte: Ed. Autêntica, 2002.

SWIDERSKI, R. M. da S.; COSTA-HÜBES, T. da C. Abordagem sociointeracionista \& sequência didática: relato de uma experiência. Línguas \& Letras, vol. 10, n.18, $1^{\circ}$ sem. 2009. 
Recebido em: 05/06/2017

Aprovado em: 23/07/2017

Publicado em: 01/02/2018 